\title{
REVIEW
}

\section{Application of Evidence-based Nursing in Elderly Patients with Ar- rhythmia after Acute Myocardial Infarction}

\author{
Xiongxin Wang* Man Xu \\ Hubei Yingcheng Chinese Medicine Hospital, Yingcheng, Hubei, 432400 China.
}

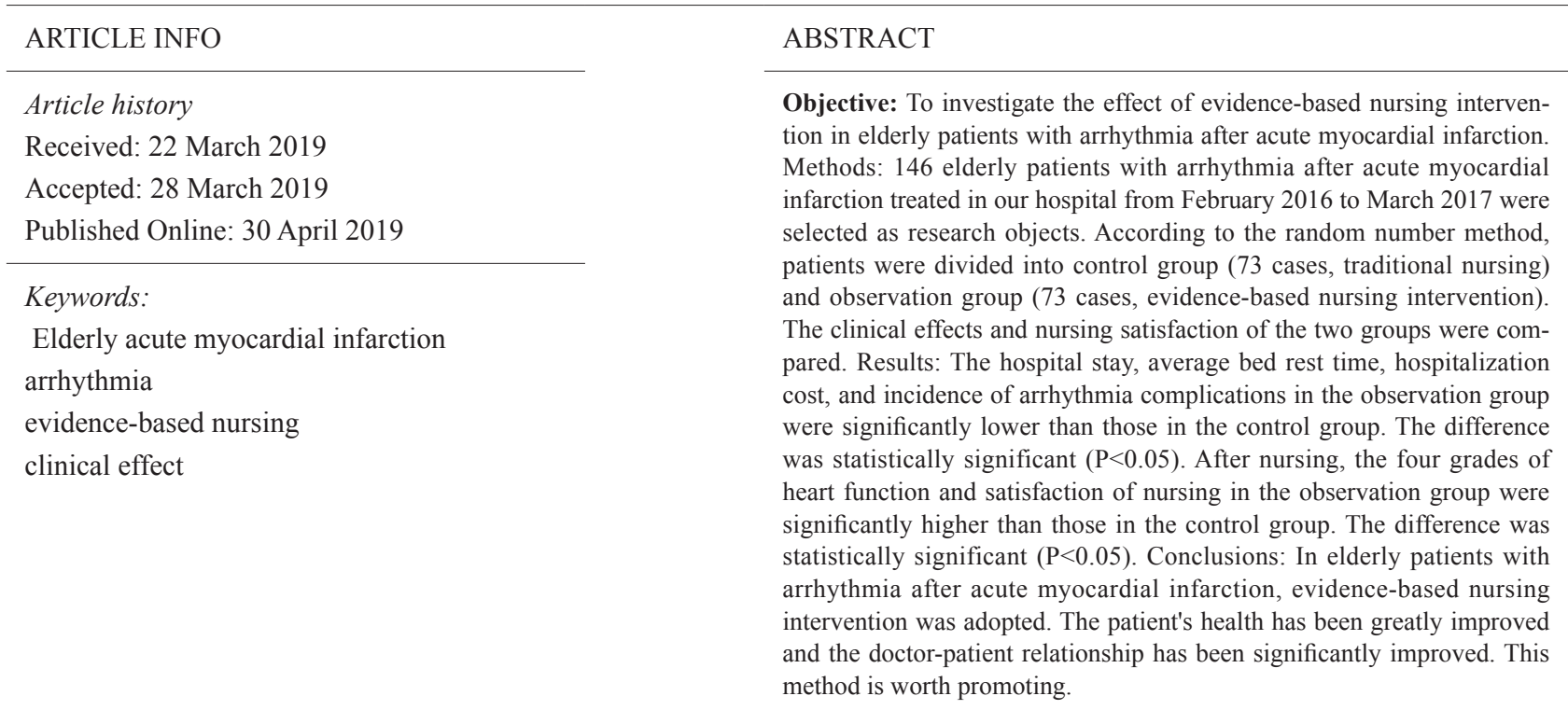

\section{Introduction}

A cute myocardial infarction refers to the persistent severe ischemic symptoms of the patient's myocardium, which is a common clinical heart disease ${ }^{[1]}$. This symptom can easily lead to serious complications. Arrhythmia is one of the most common complications of this disease. About three-quarters of patients with acute myocardial infarction have frequent heart rate symptoms. The disease has a rapid onset and a high mortality rate. When patients have acute myocardial infarction complicated with arrhythmia symptoms, if they are not effectively treated and cared for, the blood supply to the myocardium and organs will be seriously affected, which will lead to clinical symptoms such as shock, nausea and vomiting, and even death ${ }^{[2]}$. For this reason, evidence-based nursing was adopted for elderly patients with arrhythmia after acute myocardial infarction, and good clinical efficacy was achieved.

\section{Materials and Methods}

\subsection{Clinical Information}

A total of 146 elderly patients with arrhythmia after

*Corresponding Author:

Xiongxin Wang,

Hubei Yingcheng Chinese Medicine Hospital, Yingcheng, Hubei, 432400 China;

E-mail:wangxiongxin@163.com. 
acute myocardial infarction who were treated in our hospital from February 2016 to March 2017 were selected as subjects. According to the random number method, they were divided into the control group $(73$ cases) and the observation group ( 73 cases). The patients in the observation group were between 51-82 years old and the average age was $(65.4 \pm 4.3)$ years old. Among them, there were 46 male patients and 27 female patients. The patients in the control group were between 51-82 years old and the average age was $(65.4 \pm 4.3)$ years old. Among them, there were 41 male patients and 32 female patients. All the selected patients met the relevant diagnostic criteria. Patients with mental disorders were excluded. There were no significant differences in age and condition between the two groups $(\mathrm{P}>0.05)$, which were comparable. This study has been approved by relevant departments, and the participants are informed.

\subsection{Therapeutic Method}

Control group: Traditional nursing. Bed rest, emotional stabilization, dietary adjustment, ECG monitoring, etc.

Observation group: On the basis of the control group, evidence-based nursing intervention was conducted. First, the question was raised. The predisposing factors of acute myocardial infarction (AMI) complicated with arrhythmia are numerous and complicated. It is most closely related to myocardial ischemic necrosis and inflammatory edema. Increased metabolites, acid-base imbalances, and hypoxemia are also key predisposing factors. Therefore, treatment methods, reduction in the incidence of pain and arrhythmia, and health presentations have been studied. Second, in order to find the answer, the information was collected. Knowledge is accumulated through the network and related books. Third, the collected information was screened. Fourth, the practical application. The specific measures are as follows: First, the nursing work team was formed. Individualized care is provided by experienced caregivers to develop complete care measures. Second, the patient's heart rhythm was closely monitored. Most of the heart rate disorders occur 1-2 weeks after acute myocardial infarction. Particular attention should be paid on the first day of infarction. In the early hours of the morning and at noon, the inspections were strengthened. Once symptoms such as palpitations, shortness of breath, and fainting appear, rescue measures are taken immediately. Drugs and instruments are prepared in advance. Third, standardize records. The disease and examination results were updated daily, and the causes and countermeasures were summarized. Fourth, health education. Knowledge of the disease, treatment objectives and precautions are explained to guide patients to cope with emergencies, re- lieve tension, and reduce anxiety, fear and other adverse emotions, so as to improve treatment compliance. Fifth, psychological care. Psychological knowledge and communication skills are used to eliminate the negative factors of patients, establish good communication relationships, increase patients' sense of trust, and release patients' stress. Sixth, analgesic and sedative care. Irritability, fear and severe pain are the main factors that induce arrhythmias. If the symptom cannot be alleviated in time, effective analgesia and sedation must be taken for the patient. Myocardial necrosis, myocardial oxygen consumption and stress should be avoided as much as possible. Seventh, digestive care. Constipation should be prevented. Patients should have more meals a day but less food at each, with more fruits, vegetables and fiber, and avoid irritating foods. Moderate massage ensures smooth stools and reduces the burden on the heart.

\subsection{Observed Indicator}

The clinical effect (including hospital stay, average bed time, hospitalization costs and complication rate), cardiac function grading and patients satisfaction with nursing were compared between the two groups.

The satisfaction of nursing was evaluated by the relevant scale, which was divided into very satisfied, satisfied, generally satisfied, and unsatisfied. Satisfaction $=$ number of cases of (very satisfied + satisfied + generally satisfied) / total number of cases $\times 100 \%{ }^{[3]}$.

Cardiac functional grading (NYHA) is divided into four levels. Level I: The patient has heart disease and the daily activities are not restricted. Level II: Physical activity is slightly restricted. Fatigue, palpitations and asthma symptoms were relieved at rest. Level III: Physical activity is significantly restricted. Fatigue, palpitation and asthma were obvious. Level IV: Patients are not allowed to engage in any physical activity. There is a symptom of heart failure at rest, which is aggravated after physical activity ${ }^{[4]}$.

\subsection{Statistical Treatment}

SPSS20.0 statistical software was used to process the data. The measurement data is represented by the mean $\bar{x} \pm s$ false. The count data is represented by $(\mathrm{n}, \%) . \mathrm{P}=0.05$ is the cutoff value. $\mathrm{P}<0.05$ indicates that the difference was statistically significant.

\section{Results}

\subsection{Comparison of Clinical Effects between the Two Groups}

Clinical observation: The length of hospital stay in the 
observation group was $(21.5 \pm 4.2)$ days. The average bed-rest time was $(2.3 \pm 1.0)$ days. The hospitalization cost is $(5153.2 \pm 152.1)$ yuan. The incidence of arrhythmia complications was $8.2 \%$. The clinical effects of the observation group were significantly lower than the control group. The difference was statistically significant $(\mathrm{P}<$ 0.05) (Table 1).

Table 1. Comparison of clinical effects between the two groups

\begin{tabular}{|c|c|c|c|c|c|}
\hline Groups & $\begin{array}{c}\text { Number } \\
\text { of cases }\end{array}$ & $\begin{array}{c}\text { Hospital } \\
\text { stay } \\
\text { (d) }\end{array}$ & $\begin{array}{c}\text { Average } \\
\text { bed time } \\
\text { (d) }\end{array}$ & Hospital costs & $\begin{array}{c}\text { Incidence of } \\
\text { arrhythmia } \\
\text { complications } \\
\text { (\%) }\end{array}$ \\
\hline $\begin{array}{c}\text { Control } \\
\text { group }\end{array}$ & 73 & $28.6 \pm 5.3$ & $5.8 \pm 1.3$ & $7855.8 \pm 213.3$ & $17(23.2)$ \\
\hline $\begin{array}{c}\text { Observation } \\
\text { group }\end{array}$ & 73 & $21.5 \pm 4.2$ & $2.3 \pm 1.0$ & $5153.2 \pm 152.1$ & $6(8.2)$ \\
\hline $\mathbf{P}$ & & $<0.05$ & $<0.05$ & $<0.05$ & $<0.05$ \\
\hline
\end{tabular}

\subsection{Comparison of Cardiac Functional Grading between the two Groups}

After nursing, in terms of cardiac function, the observation group had 25 patients with grade I (34.3\%), 23 patients with grade II (31.6\%), 17 patients with grade III (23.2\%), and 8 patients with grade IV $(10.9 \%)$, which were significantly better than the control group. The difference was statistically significant $(\mathrm{P}<0.05)$ (Table 2$)$.

Table 2. Comparison of cardiac functional grading between the two groups

\begin{tabular}{|c|c|c|c|c|c|}
\hline Groups & $\begin{array}{c}\text { Number } \\
\text { of cases }\end{array}$ & $\begin{array}{c}\text { Level I } \\
{[\mathbf{n}(\%)]}\end{array}$ & $\begin{array}{c}\text { Level II } \\
{[\mathbf{n}(\%)]}\end{array}$ & $\begin{array}{c}\text { Level III } \\
{[\mathbf{n}(\%)]}\end{array}$ & $\begin{array}{c}\text { Level IV } \\
{[\mathbf{n}(\%)]}\end{array}$ \\
\hline $\begin{array}{c}\text { Observation } \\
\text { group }\end{array}$ & 73 & $25(34.3 \%)$ & $23(31.6 \%)$ & $\begin{array}{c}17 \\
(23.2 \%)\end{array}$ & $\begin{array}{c}8 \\
(10.9)\end{array}$ \\
\hline $\begin{array}{c}\text { Control } \\
\text { group }\end{array}$ & 73 & $\begin{array}{c}17 \\
(23.2 \%)\end{array}$ & $\begin{array}{c}15 \\
(20.6 \%)\end{array}$ & $\begin{array}{c}22 \\
(30.1 \%)\end{array}$ & $\begin{array}{c}19 \\
(26.1)\end{array}$ \\
\hline $\mathbf{P}$ & & & & & $<0.05$ \\
\hline
\end{tabular}

\subsection{Comparison of Nursing Satisfaction between the Two Groups}

In the observation group, the great satisfaction rate was $53.4 \%$, the satisfaction rate was $19.2 \%$, the general satisfaction rate was $20.6 \%$, and the nursing satisfaction was $93.1 \%$, which was significantly higher than the control group of $72.6 \%$. The difference was statistically significant $(\mathrm{P}<0.05)$ (Table 3$)$.
Table 3. Comparison of nursing satisfaction between the two groups

\begin{tabular}{|c|c|c|c|c|c|}
\hline $\begin{array}{c}\text { Groups } \\
\mathbf{N = 7 3}\end{array}$ & $\begin{array}{c}\text { Very } \\
\text { satisfied }\end{array}$ & Satisfied & $\begin{array}{c}\text { Generally } \\
\text { satisfied }\end{array}$ & Not satisfied & $\begin{array}{c}\text { Nursing satis- } \\
\text { faction\% }\end{array}$ \\
\hline $\begin{array}{c}\text { Observation } \\
\text { group }\end{array}$ & $\begin{array}{c}39 \\
(53.4 \%)\end{array}$ & $\begin{array}{c}14 \\
(19.2 \%)\end{array}$ & $\begin{array}{c}15 \\
(20.6 \%)\end{array}$ & $\begin{array}{c}5 \\
(6.8 \%)\end{array}$ & 93.1 \\
\hline $\begin{array}{c}\text { Control } \\
\text { group }\end{array}$ & $\begin{array}{c}21 \\
(28.8 \%)\end{array}$ & $\begin{array}{c}17 \\
(23.3 \%)\end{array}$ & $\begin{array}{c}15 \\
(20.6 \%)\end{array}$ & $\begin{array}{c}20 \\
(27.3 \%)\end{array}$ & 72.6 \\
\hline $\mathbf{P}$ & & & & & $<0.05$ \\
\hline
\end{tabular}

\section{Discussion}

Acute myocardial infarction refers to myocardial necrosis caused by persistent and severe ischemia of the heart muscle due to a sharp decrease or interruption of coronary blood supply. Arrhythmia often occurs in the clinic. The incidence rate can reach $75 \%$. With the continuous improvement of medical technology, clinical thrombolytic therapy has been widely used, and the mortality rate of patients has been greatly reduced. However, complications after myocardial infarction are difficult to avoid ${ }^{[5]}$. Patients often have chest tightness, shortness of breath, palpitations, and lack of strength in clinical practice. In severe cases, shock, ventricular fibrillation, or even sudden death may occur. Although arrhythmia is often relieved by treatment, the recurrence rate is difficult to control. It is very important to carry out effective nursing intervention for patients. Traditional nursing mainly adopts passive nursing. It's just for therapeutic purposes. The nursing staff lacks initiative and the nursing effect is extremely unsatisfactory ${ }^{[6]}$.

As a new type of nursing, evidence-based nursing can fully integrate clinical experience with clinical conditions ${ }^{[7]}$. The relationship between traditional nursing and treatment has been changed, so that the two become mutually reinforcing and complementary. They worked together for the early recovery of patients. Evidence-based nursing science develops plans for care, rehabilitation, and emergency response, and provides overall guidance around patient rehabilitation. Nursing interventions were carried out through psychological intervention, health education and other aspects. Evidence-based nursing staff have accumulated working experience and improved the quality of nursing. Patients' recovery is more reliably guaranteed. It has been recognized and accepted by patients and their families. Based on the diagnosis, evidence-based care develops a standard care model. According to the standardized care process, the patient's needs are met as much as possible. Therefore, the patient's compliance with medical treatment is reduced, medical expenses are reduced, and 
the doctor-patient relationship becomes more harmonious. Evidential -based nursing has gradually received keen attention since its birth in the 1990s. Its nursing purpose is to make the most suitable nursing plan for every patient. This method has been widely used abroad. Through the process of asking questions, inquiring and satisfying, the program formulates personalized and specialized nursing programs, thus improving the effect of treatment.

Based on the analysis of actual cases, the hospitalization time, average bed time, hospitalization cost and incidence of arrhythmia complications in the observation group were significantly lower than those in the control group. The difference was statistically significant $(\mathrm{P}<0.05)$. After nursing, the four grades of cardiac function of the patients in the observation group were significantly better than the control group. The difference was statistically significant $(\mathrm{P}<0.05)$. The nursing satisfaction of the observation group was $93.1 \%$, which was significantly higher than that of the control group $(72.6 \%)$. The difference was statistically significant $(\mathrm{P}<0.05)$. In summary, evidence-based nursing intervention for elderly patients with arrhythmia after acute myocardial infarction is significantly better than traditional nursing. The patient's symptoms were effectively improved, and the doctor-patient relationship was significantly improved. This method is worthy of clinical promotion.

\section{References}

[1] Wei Ju. Application of Evidence-based Nursing in
Patients with Arrhythmia after Acute Myocardial Infarction [J]. Journal of Clinic Nursing's Practicality, 2016,1(3):62-66.

[2] Ping Ma. Observation of the Effect of Circulation Nursing on Arrhythmia after Acute Myocardial Infarction $[\mathrm{J}]$. World Latest Medicine Information, 2017,17(49):169-173.

[3] Huizhi Shi. Application Effect of Evidence-Based Nursing in Patients with Arrhythmia after Acute Myocardial Infarction [J]. World Latest Medicine Information, 2016,16(80):370.

[4] Wenfang Niu and Zhijun Song. Application of Evidence-Based Nursing in the Treatment of Arrhythmia after Acute Myocardial Infarction [J]. World Latest Medicine Information, 2016,16(53):266-271.

[5] Hongmei Su, Yun Zhou, Jing, Cao et al. Comparative Study of Evidence-Based Nursing and Routine Nursing On Arrhythmia after Acute Myocardial Infarction in Elderly Patients [J]. Chinese Journal of Evidence-Based Cardiovascular Medicine, 2016,8(9):1106-1107.

[6] Yongfen Liu. Application of Evidence-Based Nursing in the Treatment of Arrhythmia after Acute Myocardial Infarction [J]. China Practical Medicine, 2014,9(11):235-236.

[7] Yirong Yang. Effect of Evidence-Based Nursing on Rehabilitation of Patients with Arrhythmia after Acute Myocardial Infarction [J]. Medical Innovation of China, 2014,11(17):102-104. 